\title{
The efficacy of GABAergic precursor cells transplantation in alleviating neuropathic pain in animal models: a systematic review and meta-analysis
}

\author{
Shaghayegh Askarian-Amiri ${ }^{1}$, Solmaz Nasseri Maleki ${ }^{2}$, Seyedeh Niloufar Rafiei Alavi ${ }^{2}$, \\ Arian Madani Neishaboori ${ }^{2}$, Amirmohammad Toloui ${ }^{2}$, Mohammed I. M. Gubari ${ }^{3}$, Arash Sarveazad ${ }^{4,5}$, \\ Mostafa Hosseini $^{6,7}$, and Mahmoud Yousefifard ${ }^{2}$
}

'Institute de Biologie Structurale (IBS), Grenoble Alpes University, CEA, CNRS, Grenoble, France

${ }^{2}$ Physiology Research Center, Iran University of Medical Sciences, Tehran, Iran

${ }^{3}$ Department of Family and Community Medicine, College of Medicine, University of Sulaimani, Sulaimani, Iraq

${ }^{4}$ Colorectal Research Center, Iran University of Medical Sciences, Tehran, Iran

${ }^{5}$ Nursing Care Research Center, Iran University of Medical Sciences, Tehran, Iran

${ }^{6}$ Pediatric Chronic Kidney Disease Research Center, Tehran University of Medical Sciences, Tehran, Iran

${ }^{7}$ Department of Epidemiology and Biostatistics, School of Public Health, Tehran University of Medical Sciences, Tehran, Iran

Received August 3, 2021

Revised October 14, 2021

Accepted October 14, 2021

Handling Editor: Hyun Kang

\section{Correspondence}

Mahmoud Yousefifard

Physiology Research Center, Iran

University of Medical Sciences, Hemmat

Highway, P.O Box: 14665-354, Tehran

1449614535, Iran

Tel: +982186704771

Fax: +982186704771

E-mail: yousefifard.m@iums.ac.ir

Mostafa Hosseini

Department of Epidemiology and Biostatistics, School of Public Health, Tehran University of Medical Sciences, Poursina Ave, Tehran 1417613151, Iran Tel: +982188989125

Fax: +982188989127

E-mail:mhossein110@yahoo.com
Background: Current therapies are quite unsuccessful in the management of neuropathic pain. Therefore, considering the inhibitory characteristics of GABA mediators, the present systematic review and meta-analysis aimed to determine the efficacy of GABAergic neural precursor cells on neuropathic pain management. Methods: Search was conducted on Medline, Embase, Scopus, and Web of Science databases. A search strategy was designed based on the keywords related to GABAergic cells combined with neuropathic pain. The outcomes were allodynia and hyperalgesia. The results were reported as a pooled standardized mean difference (SMD) with a 95\% confidence interval (95\% Cl).

Results: Data of 13 studies were analyzed in the present meta-analysis. The results showed that administration of GABAergic cells improved allodynia (SMD = 1.79; 95\% Cl: $0.87,271 ; P<0.001)$ and hyperalgesia (SMD = 1.29; 95\% Cl: 0.26, 2.32; $P$ $=0.019$ ). Moreover, the analyses demonstrated that the efficacy of GABAergic cells in the management of allodynia and hyperalgesia is only observed in rats. Also, only genetically modified cells are effective in improving both of allodynia, and hyperalgesia.

Conclusions: A moderate level of pre-clinical evidence showed that transplantation of genetically-modified GABAergic cells is effective in the management of neuropathic pain. However, it seems that the transplantation efficacy of these cells is only statistically significant in improving pain symptoms in rats. Hence, caution should be exercised regarding the generalizability and the translation of the findings from rats and mice studies to large animal studies and clinical trials.

Key Words: Bibliometrics; Cell Engineering; Chronic Pain; GABAergic Neurons; Gamma-Aminobutyric Acid; Hyperalgesia; Neural Stem Cells; Neuralgia; Pain Management; Spinal Cord Injuries. (c) This is an open-access article distributed under the terms of the Creative Commons Attribution Non-Commercial License (http://creativecommons.org/licenses/by-nc/4.0/), which permits unrestricted non-commercial use, distribution, and reproduction in any medium, provided the original work is properly cited.

(c) The Korean Pain Society, 2022
Author contributions: Shaghayegh Askarian-Amiri: Investigation; Solmaz Nasseri Maleki: Investigation; Seyedeh Niloufar Rafiei Alavi: Investigation; Arian Madani Neishaboori: Investigation; Amirmohammad Toloui: Investigation; Mohammed I. M. Gubari: Investigation; Arash Sarveazad: Investigation; Mostafa Hosseini: Formal analysis; Mahmoud Yousefifard: Study conception. 


\section{INTRODUCTION}

Neuropathic pain is caused by a primary lesion or dysfunction in the nervous system and is subsequent to an injury to the peripheral or central nervous system (CNS). Hyperalgesia and allodynia are two main symptoms of neuropathic pain [1]. Spinal cord injury (SCI) is an important mechanism causing neuropathic pain, which is very challenging to manage. Following SCI, a majority of the patients suffer from chronic pain with a severity ranging from moderate to severe [2-5]. The current findings indicate that the experienced pain in regions below the injury has a central origin and is associated with functional impairments in the white and gray matter of the spinal cord. This pain is characterized by inappropriate responses to painful or non-painful stimulations of the skin [5].

Medication therapy is the main basis of neuropathic pain management in the clinic [6]. But these medications can only alleviate the pain, temporarily [7]. Additionally, the undesirable complications, accompanied by the longterm use of medications, pose major obstacles to the use of these treatments [8]. Since neuropathic pain is caused by an injury to the central or peripheral nervous system, the pain will continue to affect patients, unless the injured area is somehow repaired or neural pathways are strengthened. Gene therapy is one appropriate strategy which has shown to be beneficial in delivering active biological molecules [9]. Hence, extensive research is being conducted on the management of neuropathic pain through transplantation of genetically-modified cells.

GABA and glycine are two key CNS mediators, with inhibitory effects on pain transmission pathways in the central cord. Injection of GABA antagonists stimulates severe pain, similar to allodynia and hyperalgesia [10]. On the other hand, administration of GABA neurotransmitter helps with pain management in a dose-dependent manner. However, systemic administration of GABA agonists has shown unsatisfactory results [11]. One of the solutions to increase the efficacy of these neurotransmitters is through intrathecal administration, and transplantation of GABAergic neural precursor cells may be beneficial in this regard $[12,13]$. Recent findings emphasize on the favorable effects of using these cells in alleviating chronic pain. Moreover, injection of these cells has improved and reduced neuropathic pain in animal models [14-16].

Although pre-clinical studies have demonstrated that administration of GABAergic neural precursor cells has significant effects on the management of neuropathic pain, there is no consensus over the matter. Conducting a systematic review and meta-analysis is one way to reach a complete and comprehensive conclusion. Accordingly, the present study was conducted to determine the efficacy of GABAergic neural precursor cells on animal models of neuropathic pain.

\section{MATERIALS AND METHODS}

The current study was designed based on instructions for performing meta-analysis on clinical trials in animal studies. Our meta-analysis aimed to review animal studies. Therefore, PICO in the current study is as follows: P: Animal models (rats and mice) with neuropathic pain, I: Intrathecal or intraspinal transplantation of GABAergic cells, C: Comparison with the control group (without treatment or treatment with drug vehicle) and O: pain alleviation in the studied animals based on Allodynia and Hyperalgesia assessment tests.

On the basis of achieving the above-mentioned aims, an extensive search was performed in Medline (using PubMed), ISI Web of Science, Embase, and Scopus electronic databases, using related keywords and their proper combinations, searching for the articles published through the end of January 20, 2021. The search strategy was designed based on the keywords presented in Appendix 1.

Keywords were selected according to the words related to neuropathic pain and GABAergic neural precursor cells' transplantation, and were chosen on three bases. First, MeSH and Emtree were searched for the keywords. Then, titles and abstracts of the relevant articles were screened to find additional keywords. Finally, with the help of experts in the field of SCI research, the keywords list was completed. Combining the selected keywords to design search terms, the search was performed in the electronic databases. Moreover, a hand search was performed using relevant articles' references and related journals, to find additional and possibly missing articles. Finally, for finding gray literature, three strategies were adopted including searching through ProQuest's Dissertations and Theses section, contacting authors of the relevant articles to access their unpublished or preprint data and searching in the Google and Google Scholar search engines.

Controlled studies assessing the effects of GABAergic neural precursor cells' transplantation in managing neuropathic pain were included. The term "controlled studies" refers to the studies which performed their experiments on a no-treatment control group (placebo group or vehicle group), in addition to performing experiments on the group treated with the transplanted cells. Including articles was not limited to their published date or their language, as part of the existing literature was in Chinese or Japanese. The target was animal studies performed on mice and rats, irrespective of the animals' age, sex, and 
strain, in which neuropathic pain was created using central or peripheral mechanisms. The assessed intervention was intraspinal or intrathecal transplantation of GABAergic neural precursor cells. The animals' pain was considered to be the assessed outcome.

Studies not having a control group, studies in which pain was not evaluated, and studies in which the number of transplanted GABAergic neural precursor cells was not reported were excluded. It is worth mentioning that review articles were excluded as well. Since, the onset of pain in the animal models occurs at least four weeks after the injury, studies which performed less than four weeks of follow up were also excluded.

The articles obtained from the hand search and systematic search were gathered using the EndNote program (version X7; Thomson Reuters, Toronto, ON, Canada), and duplicates were eliminated. Two independent reviewers performed the initial screening, reviewing titles and abstracts of the gathered articles. Next, full texts of the relevant articles were studied, and, based on the inclusion and exclusion criteria, included articles were selected. Every disagreement was resolved, using a third reviewer's opinion.

The extracted data from the articles included information related to the study design, sample, and control groups' characteristics (age, sex, mechanism of neuropathic pain inducement), sample size, type of the donated cell, species which transplanted cells were obtained from, number of the transplanted cells, interval time between inducement of the neuropathic pain and transplantation of the cells, follow-up period, and the severity of the animals' pain. Since in most cases, the assessed outcome was reported in multiple stages, the last report in the article was taken as input to the present meta-analysis. In cases of the results being reported in graphs, the graph data extraction method by Sistrom and Megro [17] was used. Since, some included studies had more than one experiment, we decided to record and analyze data by separate experiments. Therefore, the number of experiments exceeded the number of studies.

The quality assessment of the included studies was performed using the proposed guidelines of SYRCLE's risk of bias assessment tools [18]. This tool evaluates the risk of bias among the studies in terms of sequence generation, baseline characteristics, allocation concealment, random housing, caregiver blinding, random outcome assessment, blinding of the outcome assessor, incomplete outcome assessment, selective outcome assessment, and other risk of bias. In cases of disagreement, a third reviewer's opinion was adopted. Level of evidence was assessed using the Grading of Recommendations Assessment, Development and Evaluation (GRADE) framework [19].
All studies were summarized and categorized based on the pain's severity. Data are presented as means \pm standard deviation. Analyses were performed using the "meta" command in the STATA 17.0 statistical program (Stata Corp., College Station, TX), and the results are reported as standardized mean difference (SMD) and 95\% confidence interval (CI) by calculating Hedges' g. SMD was used to standardize the data of the different tests to a uniform scale, because of the variations between the scales of pain assessment tests performed in the studies. Since, the sample size was small and varied among included studies, we used the method proposed by Hartung, Knapp, Sidik, and Jonkman for calculating 95\% CI to avid type 1 error [20].

Neuropathic pain has two main symptoms: allodynia and hyperalgesia. Since the underlying mechanism causing the allodynia and hyperalgesia differs and various pathways are involved in their development, analyses were performed with respect to allodynia and hyperalgesia and the results are presented separately. It is worth mentioning that two types of allodynia and three types of hyperalgesia exist in the eligible articles, including mechanical allodynia, cold allodynia, mechanical hyperalgesia, heat hyperalgesia, and chemical hyperalgesia. Since the performed meta regression showed that the efficacy of the GABAergic cells' transplantation on the management of hyperalgesia and allodynia is independent of the nature of their cause, the results of the different origins of allodynia were pooled in one analysis. The same approach was adopted regarding hyperalgesia's results, as well.

Heterogeneity between the studies was evaluated using $\mathrm{I}^{2}$ statistics, and $\mathrm{I}^{2}$ values higher than $50 \%$ were considered significant (indicating heterogeneity). In cases of heterogeneity, subgroup analysis and meta-regression were performed to find the origin of the heterogeneity. In assessment of possible source of heterogeneity, a $P$ value less than 0.1 was considered significant (presence of heterogeneity). A random effect model was performed, and a 95\% CI was calculated according to the method proposed by Hartung, Knapp, Sidik, and Jonkman [20]. Outliers were identified using Galbraith plot [21]. Sensitivity analysis was performed by using the leave-one-out approach to find any possible individual studies' effect on pooled effect size. Meta-analyses were performed only when data were presented in at least two experiments. Eventually, publication bias was assessed, using the trim-and-fill method, and presenting a funnel plot. 


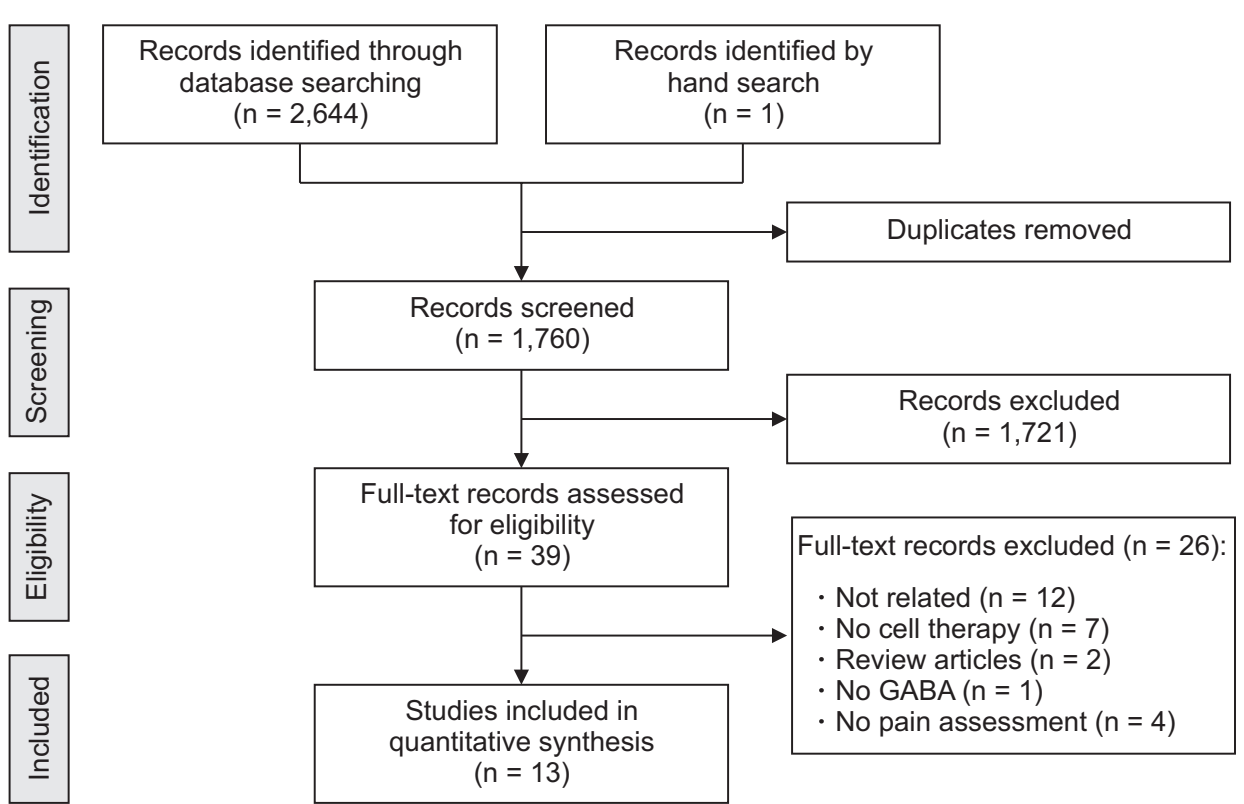

Fig. 1. PRISMA (Preferred Reporting Items for Systematic Reviews and MetaAnalyses) flow diagram of present study.

\section{RESULTS}

\section{Study characteristics}

The systematic search in the electronic databases resulted in 2,644 articles, 1,760 of which were non-duplicate records. One thousand seven hundred twenty one studies were excluded by screening the titles and abstracts and the full texts of the remaining 39 were studied (Appendix 2). Finally, the data of 13 studies were included in the present meta-analysis [15,16,22-32] (Fig. 1). These studies consisted of 17 separate experiments and involved 317 animals, 176 of which were controls and 141 animals were treated with GABAergic cells. The neuropathy pain model was peripheral in one and central in two studies, and one study used both models. The time interval between injury to transplantation of the cells ranged from three to 21 days. The site of injection was intraspinal in nine, intrathecal in three, and intracranial in one study. The origin of GABAergic cells was from the medial ganglionic eminence (intrinsic GABAergic cells) in one study, genetically modified GABAergic cells in six studies, and stem cell-derived GABAergic cells in two. The number of transplanted cells varied from $5 \times 10^{4}$ to $1 \times 10^{6}$ cells. The follow-up time was between 4 and 8 weeks. Table 1 summarizes the characteristics of the included studies.

\section{Risk of bias assessment}

Quality assessment of the studies revealed that out of all the 10 items reviewed, all articles had a high risk of bias in random outcome assessment. Additionally, 12 studies had a high risk of bias in random housing. Allocation conceal- ment in 11 studies, sequence generation in nine studies, and caregivers' and/or investigators' blinding status in nine studies a had high risk of bias. Finally, it was found that the risk of bias in selective reporting was unclear in all of the studies (Table 2).

\section{Publication bias}

The present study was conducted in two sections. In the first part, the efficacy of the transplantation of GABAergic cells on allodynia alleviation, and in the second part, the efficacy of these cells on hyperalgesia was investigated. The trim-and-fill method did not show any evidence of publication bias since there was no possibly missing study (Fig. 2).

\section{The efficacy of administration of GABAergic cells on allodynia}

The Galbraith plot showed that the allodynia assessment in chronic constriction injury (CCI) of the sciatic nerve in Eaton et al. [24] is an outlier (SMD $=19.80 ; 95 \%$ CI: 11.05 to 28.55), therefore we excluded this analysis from our metaanalysis. The present meta-analysis showed that administration of GABAergic neural precursor cells improved allodynia as one of the symptoms of neuropathic pain (SMD $=1.79 ; 95 \%$ CI: 0.87 to $2.71 ; P<0.001$ ) (Fig. 3). However, high heterogeneity was observed between the studies $\left(\mathrm{I}^{2}=\right.$ 87.08\%; $P<0.001)$.

Meta-regression demonstrated that the main sources of this heterogeneity among the studies that had evaluated the efficacy of GABAergic cells' transplantation on allodynia, were due to the administration of antibiotics (coef- 


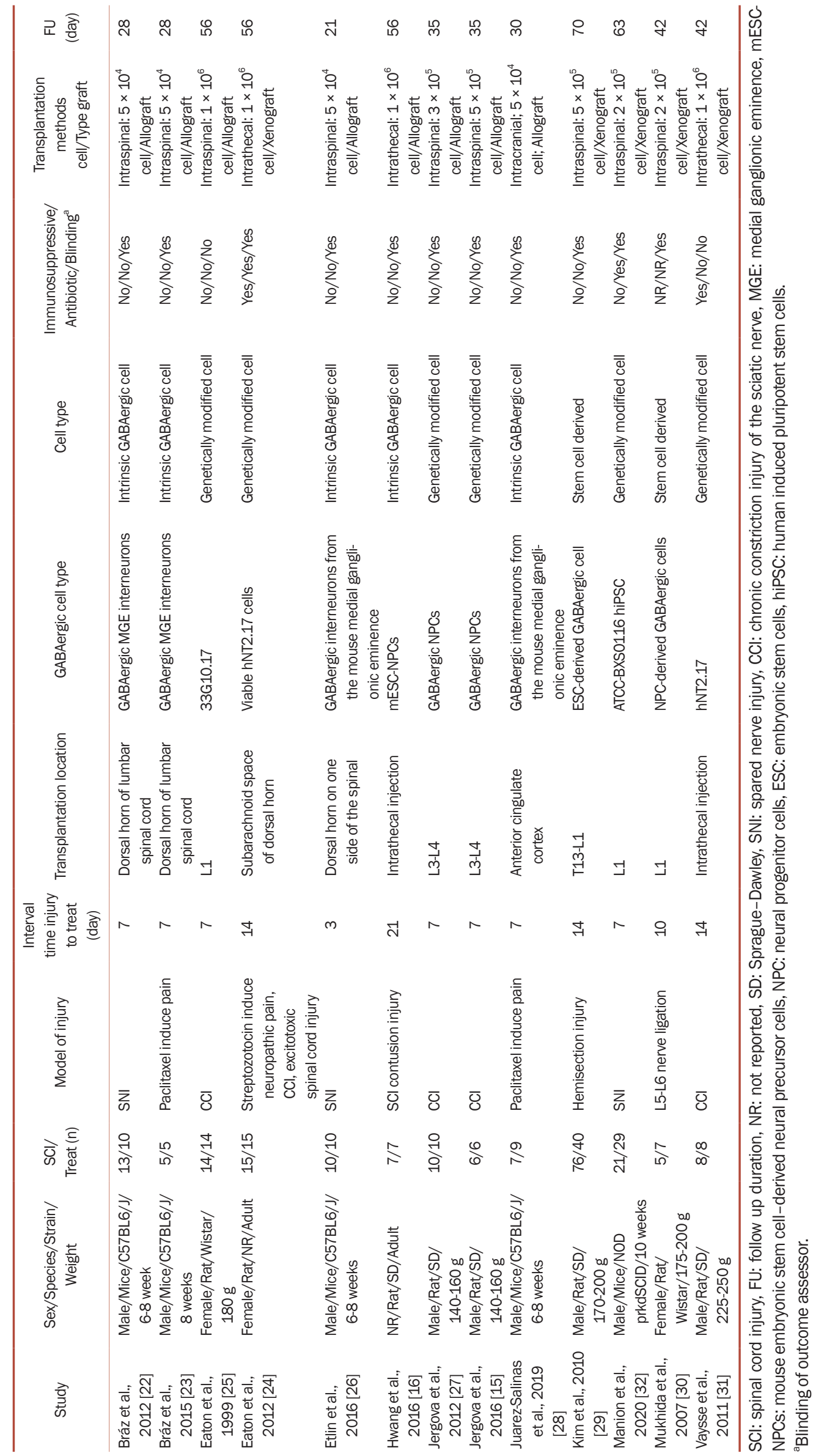


Table 2. Quality control of included studies

\begin{tabular}{|c|c|c|c|c|c|c|c|c|c|c|}
\hline Study & Item 1 & Item 2 & Item 3 & Item 4 & Item 5 & Item 6 & Item 7 & Item 8 & Item 9 & Item 10 \\
\hline Bráz et al., 2012 [22] & $x$ & $\checkmark$ & $x$ & $x$ & $\checkmark$ & $x$ & $\checkmark$ & $\checkmark$ & $?$ & $\checkmark$ \\
\hline Bráz et al., 2015 [23] & $x$ & $\checkmark$ & $x$ & $x$ & $x$ & $x$ & $\checkmark$ & $\checkmark$ & ? & $\checkmark$ \\
\hline Eaton et al., 1999 [25] & $x$ & $\checkmark$ & $x$ & $x$ & $x$ & $x$ & $x$ & $?$ & $?$ & $\checkmark$ \\
\hline Eaton et al., 2012 [24] & $x$ & $x$ & $x$ & $x$ & $x$ & $x$ & $\checkmark$ & $\checkmark$ & $?$ & $\checkmark$ \\
\hline Etlin et al., 2016 [26] & $x$ & $\checkmark$ & $x$ & $x$ & $x$ & $x$ & $\checkmark$ & $?$ & $?$ & $\checkmark$ \\
\hline Hwang et al., 2016 [16] & $\checkmark$ & $x$ & $x$ & $x$ & $x$ & $x$ & $\checkmark$ & $\checkmark$ & $?$ & $\checkmark$ \\
\hline Jergova et al., 2012 [27] & $x$ & $\checkmark$ & $x$ & $x$ & $x$ & $x$ & $\checkmark$ & $?$ & $?$ & $\checkmark$ \\
\hline Jergova et al., 2016 [15] & $x$ & $\checkmark$ & $x$ & $x$ & $x$ & $x$ & $\checkmark$ & $\checkmark$ & ? & $\checkmark$ \\
\hline Juarez-Salinas et al., 2019 [28] & $x$ & $\checkmark$ & $x$ & $x$ & $x$ & $x$ & $\checkmark$ & $?$ & $?$ & $\checkmark$ \\
\hline Kim et al., 2010 [29] & $x$ & $\checkmark$ & $\checkmark$ & $x$ & $\checkmark$ & $x$ & $\checkmark$ & $\checkmark$ & ? & $\checkmark$ \\
\hline Manion et al., 2020 [32] & $\checkmark$ & $\checkmark$ & $\checkmark$ & $\checkmark$ & $\checkmark$ & $x$ & $\checkmark$ & $\checkmark$ & $?$ & $\checkmark$ \\
\hline Mukhida et al., 2007 [30] & $\checkmark$ & $\checkmark$ & $x$ & $x$ & $\checkmark$ & $x$ & $\checkmark$ & ? & $?$ & $\checkmark$ \\
\hline Vaysse et al., 2011 [31] & $\checkmark$ & $\checkmark$ & $x$ & $x$ & $x$ & $x$ & $x$ & $\checkmark$ & $?$ & $\checkmark$ \\
\hline
\end{tabular}

Item 1: sequence generation, Item 2: baseline characteristics, Item 3: allocation concealment, Item 4: random housing, Item 5: caregivers and/or investigators blinding, Item 6: random outcome assessment, Item 7: outcome assessor blinding, Item 8: incomplete outcome data, Item 9: selective outcome reporting, Item 10: other sources of bias, $\checkmark$ : low risk of bias, $\mathbf{x}$ : high risk of bias, ?: unclear risk of bias.
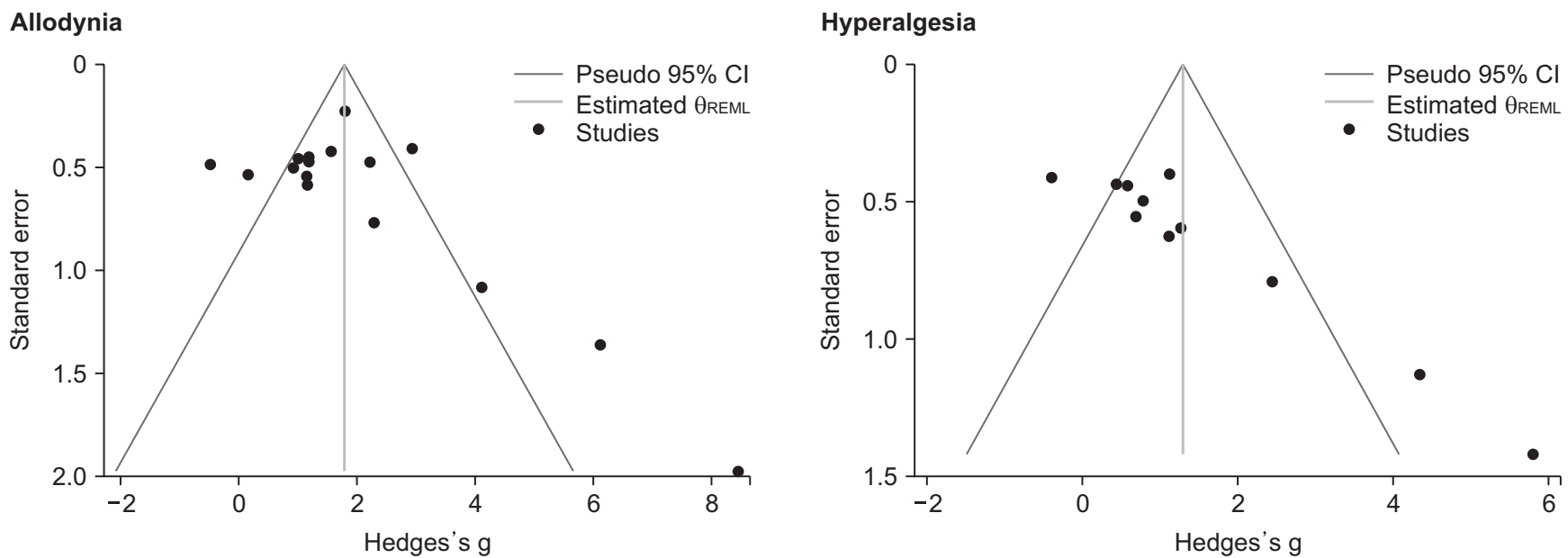

Fig. 2. Publication bias assessment across included studies. Cl: confidence interval.

ficient $=-1.96 ; P=0.033)$ and the type of graft (coefficient $=$ 1.56; $P=0.075$ ) (Table 3).

Subgroup analysis showed that the alleviating effect of GABAergic cell transplantation on allodynia is observed in rat (SMD $=1.83 ; 95 \% \mathrm{CI}: 0.66$ to $3.00 ; P=0.006)$ not mouse studies (SMD $=1.63 ; 95 \% \mathrm{CI}:-0.50$ to $3.76 ; P=0.101)$. In addition, it seems that intraspinal transplantation (SMD = 1.83; $95 \%$ CI: 0.93 to $2.73 ; P=0.001$ ) is effective in alleviating allodynia, while intrathecal transplantation did not have a significant effect (SMD $=2.76 ; 95 \% \mathrm{CI}:-2.36$ to 7.89 ; $P=0.184$ ). Cell source was another possible moderator for the efficacy of GABAergic cell transplantation. The results showed that genetically modified GABAergic cells (SMD $=2.12$; $95 \%$ CI: 0.60 to $2.94 ; P=0.008)$ can improve allodynia, while intrinsic GABAergic cells $(\mathrm{SMD}=1.19 ; 95 \% \mathrm{CI}$ : -0.67 to $3.05 ; P=0.149$ ) and stem cell derived GABAergic cells (SMD $=3.75 ; 95 \% \mathrm{CI}:-23.53$ to $31.03 ; P=0.331$ ) did not have a significant effect on allodynia. Immunosup- pressive (SMD $=3.53$; 95\% CI: -6.01 to $13.09 ; P=0.252)$ and antibiotic (SMD $=4.11 ; 95 \% \mathrm{CI}:-3.67$ to $11.80 ; P=0.151$ ) administration abolished any significant effect of GABAergic cells transplantation on allodynia compared to the nontransplanted group (animals receiving immunosuppressive/antibiotic without cell transplantation) (Table 3).

\section{The efficacy of administration of GABAergic cells on hyperalgesia}

The Galbraith plot showed that the heat hyperalgesia assessment in Eaton et al. [10] is an outlier (SMD = 7.10; 95\% CI: 5.11 to 9.10 ), therefore we excluded this analysis from our meta-analysis. The meta-analysis showed that transplantation of GABAergic cells improves hyperalgesia in the subjects, as well (SMD $=1.29 ; 95 \% \mathrm{CI}: 0.26$ to $2.32 ; P=0.019$ ) (Fig. 4). Nonetheless, high heterogeneity was found among the studies $\left(\mathrm{I}^{2}=81.5 \% ; P<0.001\right)$. 


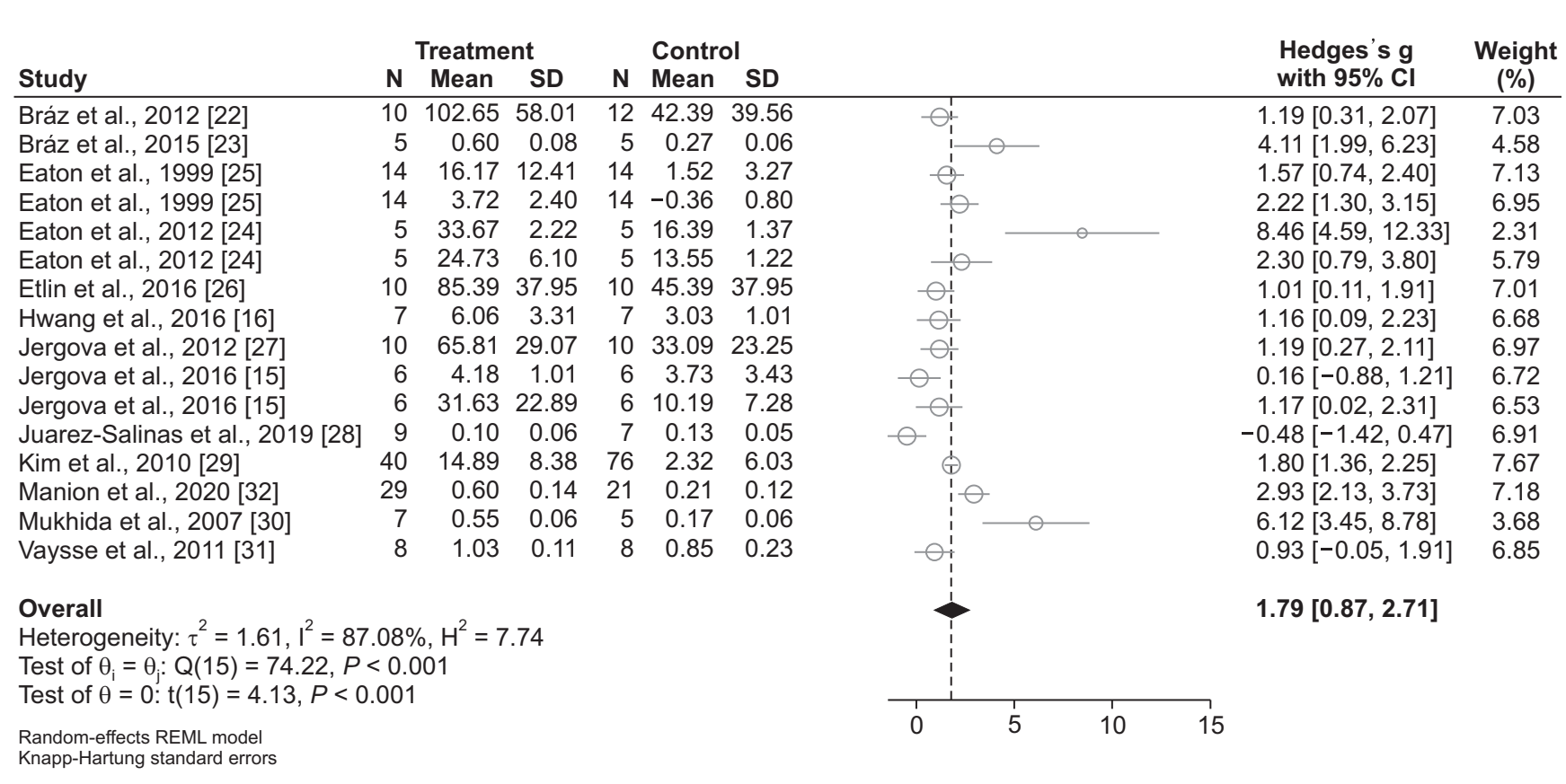

Fig. 3. Forest plot of GABAergic cell transplantation on improvement of allodynia. Since, some included studies had more than one experiment, the number of experiments exceeded the number of studies. Cl: confidence interval, SD: standard deviation.

Meta-regression demonstrated that the possible sources of heterogeneity among the studies that had evaluated the efficacy of GABAergic cells' transplantation on hyperalgesia were the route of administration (coefficient $=1.94 ; P=$ 0.035), immunosuppressive (coefficient $=-1.94 ; P=0.035$ ) and antibiotic (coefficient $=-2.97 ; P=0.002$ ) administration, the type of graft (coefficient $=1.94 ; P=0.035$ ), injury to transplantation interval (coefficient $=1.94 ; P=0.035$ ), number of transplanted cells (coefficient $=1.62 ; P=0.065$ ) and follow up duration (coefficient $=2.00 ; P=0.022$ ) (Table 4). It seems that a possible confounding effect was present among above moderators, since seven studies did not administer immunosuppressives, their route of GABAergic transplantation was intraspinal, their type of graft was xenograft and the injury to treatment interval was 0 to 7 days. Therefore, we performed a multiple meta-regression to find independent sources of heterogeneity for the efficacy of GABAergic cells on hyperalgesia. The analysis showed that antibiotic administration is the main source of heterogeneity among included studies (coefficient $=$ $-3.51 ; P=0.076)$.

Subgroup analysis showed that the alleviating effect of GABAergic cell transplantation on hyperalgesia was observed only in rats (SMD $=1.56 ; 95 \% \mathrm{CI}: 0.32$ to $2.78 ; P=$ 0.019 ) and not in mice (SMD $=0.29 ; 95 \%$ CI: -9.24 to 9.81; $P=0.768$ ). Intraspinal transplantation of GABAergic cells improved hyperalgesia (SMD $=0.63 ; 95 \%$ CI: 0.08 to 1.17; $P$ $=0.030$ ), but its intrathecal transplantation did not show a significant effect (SMD $=3.08 ; 95 \%$ CI: -0.38 to $6.55 ; P$ $=0.066$ ). Cell source was another possible moderator for the efficacy of GABAergic cell transplantation. The results showed that genetically modified GABAergic cells (SMD = 1.56; $95 \%$ CI: 0.32 to 2.78 ; $P=0.019$ ) can improve hyperalgesia, while intrinsic GABAergic cells (SMD $=0.29 ; 95 \%$ CI: -9.24 to 9.81; $P=0.768$ ) did not have significant effect on hyperalgesia. Immunosuppressives (SMD $=3.33$; 95\% CI: -0.38 to $6.55 ; P=0.066$ ) and antibiotics (SMD $=3.94 ; 95 \%$ CI: -0.25 to $8.12 ; P=0.056$ ) abolished any significant effect of GABAergic cells transplantation on hyperalgesia compared to the non-transplanted groups (animals receiving an immunosuppressive/antibiotic without cell transplantation). In addition, allograft transplantation of GABAergic cells can improve hyperalgesia and their efficacy was observed when the GABAergic cells were transplanted within the first seven days after induction of the neuropathic pain model (SMD $=0.63 ; 95 \% \mathrm{CI}: 0.08$ to 1.17 ). The number of cells was another moderator of the GABAergic cells. These cells can alleviate hyperalgesia when transplanted in doses above $5 \times 10^{5}$. It seems that the blinding status of the outcome assessor can affect the reported efficacy of GABAergic cells. The observed efficacy of GABAergic cell transplantation on hyperalgesia is significant when outcome assessor blinding was performed, while the result was not significant in unblinded outcome assessment (Table 4).

\section{Sensitivity analysis}

The leave-one-out approach was used to assess the individual studies' effect on the findings. As Fig. 5 and Fig. 6 
Table 3. Subgroup analysis for assessment of application of GABAergic cell on allodynia improvement in 16 experiments

\begin{tabular}{|c|c|c|c|c|c|c|}
\hline \multirow{2}{*}{ Subgroup } & \multirow{2}{*}{$\begin{array}{c}\text { No. of } \\
\text { experiment }^{a}\end{array}$} & \multicolumn{2}{|l|}{ Effect size } & \multirow{2}{*}{$\begin{array}{l}\text { Heterogeneity } \\
\text { ( } P \text { value })\end{array}$} & \multicolumn{2}{|c|}{ Meta-regression } \\
\hline & & $\operatorname{SMD}(95 \% \mathrm{Cl})$ & $P$ value & & Coef. (95\% Cl) & $P$ value \\
\hline \multicolumn{7}{|l|}{ Species } \\
\hline Mice & 5 & $1.63(-0.50,3.76)$ & 0.101 & $90.7 \%(<0.001)$ & Ref. & \\
\hline Rat & 11 & $1.83(0.66,3.00)$ & 0.006 & $83.3 \%(<0.001)$ & $0.32(-1.78,2.42)$ & 0.749 \\
\hline \multicolumn{7}{|l|}{ Pain inducing model } \\
\hline Peripheral & 13 & $1.92(0.66,3.18)$ & 0.006 & $90.4 \%(<0.001)$ & Ref. & \\
\hline Central & 3 & $1.75(0.94,2.56)$ & 0.012 & $0.0 \%(0.419)$ & $-0.11(-2.58,2.36)$ & 0.923 \\
\hline \multicolumn{7}{|l|}{ Route of transplantation } \\
\hline Intraspinal & 11 & $1.83(0.93,2.73)$ & 0.001 & $82.2 \%(<0.001)$ & Ref. & \\
\hline Intrathecal & 4 & $2.76(-2.36,7.89)$ & 0.184 & $93.9 \%(<0.001)$ & $0.25(-2.00,2.50)$ & 0.816 \\
\hline Intracranial & 1 & NA & NA & NA & NA & NA \\
\hline \multicolumn{7}{|l|}{ Cell source } \\
\hline Intrinsic GABAergic ${ }^{\mathrm{b}}$ & 5 & $1.19(-0.67,3.05)$ & 0.149 & $83.9 \%(0.001)$ & Ref. & \\
\hline Genetically modified & 9 & $2.12(0.60,2.94)$ & 0.008 & $77.1 \%(<0.001)$ & $0.64(-1.47,2.75)$ & 0.522 \\
\hline Stem cell derived & 2 & $3.75(-23.53,31.03)$ & 0.331 & $89.8(0.002)$ & $2.03(-1.26,5.32)$ & 0.206 \\
\hline \multicolumn{7}{|l|}{ Immunosuppressive } \\
\hline Yes & 3 & $3.53(-6.01,13.09)$ & 0.252 & $94.4 \%(<0.001)$ & Ref. & \\
\hline No & 12 & $1.42(0.73,2.10)$ & $<0.001$ & $79.8 \%(<0.001)$ & $-1.02(-3.29,1.25)$ & 0.349 \\
\hline NR & 1 & NA & NA & NA & NA & NA \\
\hline \multicolumn{7}{|l|}{ Antibiotic } \\
\hline Yes & 3 & $4.11(-3.67,11.80)$ & 0.151 & $91.7 \%(0.014)$ & Ref. & \\
\hline No & 12 & $1.22(0.64,1.83)$ & $<0.001$ & $68.6 \%(<0.001)$ & $-1.96(-3.73,-0.19)$ & 0.033 \\
\hline NR & 1 & NA & NA & NA & NA & NA \\
\hline \multicolumn{7}{|c|}{ Blinding of outcome assessor } \\
\hline Yes & 13 & $1.96(0.71,3.22)$ & 0.005 & $91.4 \%(<0.001)$ & Ref. & \\
\hline No & 3 & $1.59(0.02,3.15)$ & 0.049 & $42.7 \%(0.170)$ & $-0.32(-2.75,2.12)$ & 0.785 \\
\hline \multicolumn{7}{|l|}{ Type of graft } \\
\hline Allograft & 10 & $1.18(0.44,1.92)$ & 0.005 & $69.1 \%(<0.001)$ & Ref. & \\
\hline Xenograft & 6 & $3.28(0.53,6.04)$ & 0.028 & $94.7 \%(<0.001)$ & $1.56(-0.18,3.31)$ & 0.075 \\
\hline \multicolumn{7}{|l|}{ Injury to transplant } \\
\hline 0 to 7 days & 10 & $1.41(0.54,2.27)$ & 0.005 & $81.2 \%(<0.001)$ & Ref. & \\
\hline 8 days and over & 6 & $3.02(0.05,5.99)$ & 0.048 & $94.8 \%(<0.001)$ & $1.13(-0.84,3.10)$ & 0.238 \\
\hline \multicolumn{7}{|l|}{ No. of cell (cell/kg) } \\
\hline$\leq 5 \times 10^{5}$ & 10 & $1.68(0.43,2.92)$ & 0.014 & $90.6 \%(<0.001)$ & Ref. & \\
\hline $5 \times 10^{5}$ to $1 \times 10^{6}$ & 6 & $1.79(0.35,3.23)$ & 0.024 & $50.7 \%(0.005)$ & $0.44(-1.60,2.47)$ & 0.653 \\
\hline \multicolumn{7}{|l|}{ Follow up duration } \\
\hline 4 to 7 weeks & 9 & $1.41(0.03,2.80)$ & 0.046 & $87.3 \%(<0.001)$ & Ref. & \\
\hline 8 weeks and over & 7 & $2.12(1.05,3.19)$ & 0.003 & $60.3 \%(0.002)$ & $0.97(-0.82,2.76)$ & 0.265 \\
\hline
\end{tabular}

SMD: standardized mean difference, Cl: confidence interval, Coef.: coefficient, NR: not reported, NA: not applicable, Ref: reference category.

${ }^{a}$ Since, some included studies had more than one experiment, the number of experiments exceeded the number of studies. ${ }^{b}$ GABAergic cells derived from the medial ganglionic eminence.

show, omitting any of the included articles does not statistically change the effect size of GABAergic cells transplantation.

\section{Certainty of evidence}

The assessment of the evidence level according to the GRADE framework showed that the overall certainty of the evidence evaluating the efficacy of GABAergic cell transplantation on alleviating allodynia and hyperalgesia was moderate (Table 5).

\section{DISCUSSION}

A moderate level of pre-clinical evidence showed that the administration of GABAergic cells improves allodynia and hyperalgesia in neuropathic pain animal models. However, the considerable heterogeneity among the studies led the researchers to perform subgroup analysis to find the main sources of this heterogeneity. These analyses revealed that the transplanted GABAergic cells improved neuropathic pain's symptoms only in rat studies, whereas such a positive effect was not observed in mice. It was also demonstrated that only genetically modified GABAergic cells alleviate both of neuropathic pain's symptoms. Stem cell-derived cells had no significant effect on allodynia. Also, it was concluded that GABAergic interneurons from 


\begin{tabular}{|c|c|c|c|c|c|c|}
\hline \multirow[b]{2}{*}{ Study } & \multicolumn{3}{|c|}{ Treatment } & \multicolumn{3}{|c|}{ Control } \\
\hline & $\mathbf{N}$ & Mean & SD & $\mathbf{N}$ & Mean & SD \\
\hline Bráz et al., 2012 [22] & 10 & 2.22 & 17.05 & 13 & 10.10 & 20.82 \\
\hline Bráz et al., 2015 [23] & 5 & 12.22 & 3.70 & 5 & 8.41 & 2.32 \\
\hline Eaton et al., 1999 [25] & 14 & -3.15 & 1.11 & 14 & -4.10 & 0.37 \\
\hline Eaton et al., 2012 [24] & 5 & 0.65 & 1.77 & 5 & -2.72 & 0.02 \\
\hline Eaton et al., 2012 [24] & 5 & 13.73 & 0.57 & 5 & 8.38 & 1.46 \\
\hline Eaton et al., 2012 [24] & 5 & 13.59 & 0.88 & 5 & 7.93 & 0.88 \\
\hline Jergova et al., 2012 [27] & 10 & -50.56 & 29.89 & 10 & -61.90 & 17.93 \\
\hline Jergova et al., 2012 [27] & 10 & -0.32 & 2.01 & 10 & -1.34 & 1.32 \\
\hline Jergova et al., 2016 [15] & 6 & -50.38 & 22.44 & 6 & -63.61 & 11.22 \\
\hline Jergova et al., 2016 [15] & 6 & -0.33 & 0.47 & 6 & -1.41 & 1.00 \\
\hline Vaysse et al., 2011 [31] & 8 & 0.97 & 0.16 & 8 & 0.82 & 0.19 \\
\hline \multicolumn{7}{|c|}{$\begin{array}{l}\text { Overall } \\
\text { Heterogeneity: } \tau^{2}=1.30, \mathrm{I}^{2}=81.49 \%, \mathrm{H}^{2}=5.40 \\
\text { Test of } \theta_{\mathrm{i}}=\theta_{\mathrm{j}}: \mathrm{Q}(10)=37.61, P<0.001 \\
\text { Test of } \theta=0: \mathrm{t}(10)=2.79, P=0.020\end{array}$} \\
\hline $\begin{array}{l}\text { Random-effects REML model } \\
\text { Knapp-Hartung standard errors }\end{array}$ & & & & & & \\
\hline
\end{tabular}

Mean SD

Hedges's g

Weight

with $95 \% \mathrm{Cl} \quad(\%)$

Bráz et al., 2015 [23]

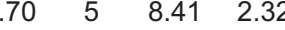

$\begin{array}{llllll}5 & 0.65 & 1.77 & 5 & -2.72 & 0.02\end{array}$

$\begin{array}{llllll}5 & 13.73 & 0.57 & 5 & 8.38 & 1.46\end{array}$

$\begin{array}{rrrrrr}5 & 13.59 & 0.88 & 5 & 7.93 & 0.88\end{array}$

$\begin{array}{llllll}10 & -50.56 & 29.89 & 10 & -61.90 & 17.93\end{array}$

$\begin{array}{llllll}10 & -0.32 & 2.01 & 10 & -1.34 & 1.32\end{array}$

$\begin{array}{llllll}-50.38 & 22.44 & 6 & -63.61 & 11.22\end{array}$

$\begin{array}{llllll}6 & -0.33 & 0.47 & 6 & -1.41 & 1.00\end{array}$

$.39[-1.20,0.41] \quad 10.66$

$\begin{array}{rr}0.39[-1.20,0.41] & 10.66 \\ 1.11[-0.11,2.33] & 9.27\end{array}$

$1.12[0.34,1.90] \quad 10.74$

$2.44[0.89,3.99] \quad 8.13$

$4.35[2.14,6.56] \quad 6.08$

$5.80[3.02,8.58] \quad 4.72$

$0.44[-0.41,1.29] \quad 10.52$

$0.58[-0.28,1.44] \quad 10.49$

$0.69[-0.39,1.77] \quad 9.76$

$1.27[0.11,2.43] \quad 9.48$

$0.78[-0.19,1.74] \quad 10.15$

$1.29[0.26,2.32]$

Fig. 4. Forest plot of GABAergic cell transplantation on improvement of hyperalgesia. Since, some included studies had more than one experiment, the number of experiments exceeded the number of studies. Cl: confidence interval, SD: standard deviation.

Table 4. Subgroup analysis for assessment of application of GABAergic cell on hyperalgesia improvement in 11 experiments

\begin{tabular}{|c|c|c|c|c|c|c|}
\hline \multirow{2}{*}{ Subgroup } & \multirow{2}{*}{$\begin{array}{c}\text { No. of } \\
\text { experiment }^{\mathrm{a}}\end{array}$} & \multicolumn{2}{|l|}{ Effect size } & \multirow{2}{*}{ Heterogeneity ( $P$ value) } & \multicolumn{2}{|c|}{ Meta-regression } \\
\hline & & SMD (95\% Cl) & $P$ value & & Coef. (95\% Cl) & $P$ value \\
\hline \multicolumn{7}{|l|}{ Species } \\
\hline Mice & 2 & $0.29(-9.24$ to 9.81$)$ & 0.768 & $75.5 \%(0.043)$ & Ref. & \\
\hline Rat & 9 & 1.56 (0.32 to 2.78$)$ & 0.019 & $81.9 \%(<0.001)$ & $1.23(-1.36,3.82)$ & 0.312 \\
\hline \multicolumn{7}{|l|}{ Origin of pain } \\
\hline Peripheral & 10 & 0.97 (0.13 to 1.81) & 0.028 & $65.4 \%(<0.001)$ & NA & NA \\
\hline Central & 1 & NA & NA & NA & NA & NA \\
\hline \multicolumn{7}{|l|}{ Route of transplantation } \\
\hline Intraspinal & 7 & 0.63 (0.08 to 1.17 ) & 0.030 & $40.2 \%(0.137)$ & Ref. & \\
\hline Intrathecal & 4 & $3.08(-0.38$ to 6.55$)$ & 0.066 & $83.8 \%(<0.001)$ & $1.94(0.17,3.72)$ & 0.035 \\
\hline Intracranial & 0 & NA & NA & NA & NA & NA \\
\hline \multicolumn{7}{|l|}{ Cell source } \\
\hline Intrinsic GABAergic ${ }^{b}$ & 2 & 0.29 (-9.24 to 9.81$)$ & 0.768 & $75.5 \%(0.043)$ & Ref. & \\
\hline Genetically modified & 9 & 1.56 (0.32 to 2.78$)$ & 0.019 & $81.9 \%(<0.001)$ & $1.23(-1.36,3.82)$ & 0.312 \\
\hline Stem cell derived & 0 & NA & NA & NA & NA & NA \\
\hline \multicolumn{7}{|l|}{ Immunosuppressive } \\
\hline Yes & 4 & 3.33 (-0.38 to 6.55$)$ & 0.066 & $83.8 \%(<0.001)$ & Ref. & \\
\hline No & 7 & 0.63 (0.08 to 1.17$)$ & 0.030 & $40.2 \%(0.137)$ & $-1.94(-3.72,-0.17)$ & 0.035 \\
\hline \multicolumn{7}{|l|}{ Antibiotic } \\
\hline Yes & 3 & $3.94(-0.25$ to 8.12$)$ & 0.056 & $59.5 \%(0.082)$ & Ref. & \\
\hline No & 8 & 0.64 (0.18 to 1.10$)$ & 0.013 & $33.0 \%(0.198)$ & $-2.97(-4.57,-1.37)$ & 0.002 \\
\hline \multicolumn{7}{|c|}{ Blinding of outcome assessor } \\
\hline Yes & 9 & 1.50 (0.10 to 2.89$)$ & 0.039 & $86.8 \%(<0.001)$ & Ref. & \\
\hline No & 2 & $0.99(-1.14$ to 3.11$)$ & 0.107 & $0.0 \%(0.588)$ & $-0.49(-3.28,2.31)$ & 0.702 \\
\hline \multicolumn{7}{|l|}{ Type of graft } \\
\hline Allograft & 7 & 0.63 (0.08 to 1.17$)$ & 0.030 & $40.2 \%(0.138)$ & Ref. & \\
\hline Xenograft & 4 & $3.08(-0.38$ to 6.55$)$ & 0.066 & $83.8 \%(<0.001)$ & $1.94(0.17,3.72)$ & 0.035 \\
\hline \multicolumn{7}{|l|}{ Injury to transplant } \\
\hline 0 to 7 days & 7 & 0.63 (0.08 to 1.17$)$ & 0.030 & $40.2 \%(0.138)$ & Ref. & \\
\hline 8 days and over & 4 & $3.08(-0.38$ to 6.55$)$ & 0.066 & $83.8 \%(<0.001)$ & $1.94(0.17,3.72)$ & 0.035 \\
\hline \multicolumn{7}{|l|}{ No. of cell (cell/kg) } \\
\hline$\leq 5 \times 10^{5}$ & 6 & $0.52(-0.11$ to 1.14$)$ & 0.087 & $35.7 \%(0.183)$ & Ref. & \\
\hline $5 \times 10^{5}$ to $1 \times 10^{6}$ & 5 & 2.54 (0.04 to 5.14$)$ & 0.048 & $87.6 \%(<0.001)$ & $1.62(-0.12,3.37)$ & 0.065 \\
\hline \multicolumn{7}{|l|}{ Follow up duration } \\
\hline 4 to 7 weeks & 7 & 0.55 (0.03 to 1.06$)$ & 0.041 & $28.2 \%(0.246)$ & Ref. & \\
\hline 8 weeks and over & 4 & $3.14(-0.10$ to 6.38$)$ & 0.054 & $82.9 \%(<0.001)$ & $2.00(0.36,3.63)$ & 0.022 \\
\hline
\end{tabular}

SMD: standardized mean difference, Cl: confidence interval, Coef.: coefficient, NA: not applicable, Ref: reference category.

${ }^{a}$ Since, some included studies had more than one experiment, the number of experiments exceeded the number of studies. ${ }^{b}$ GABAergic cells derived from the medial ganglionic eminence. 


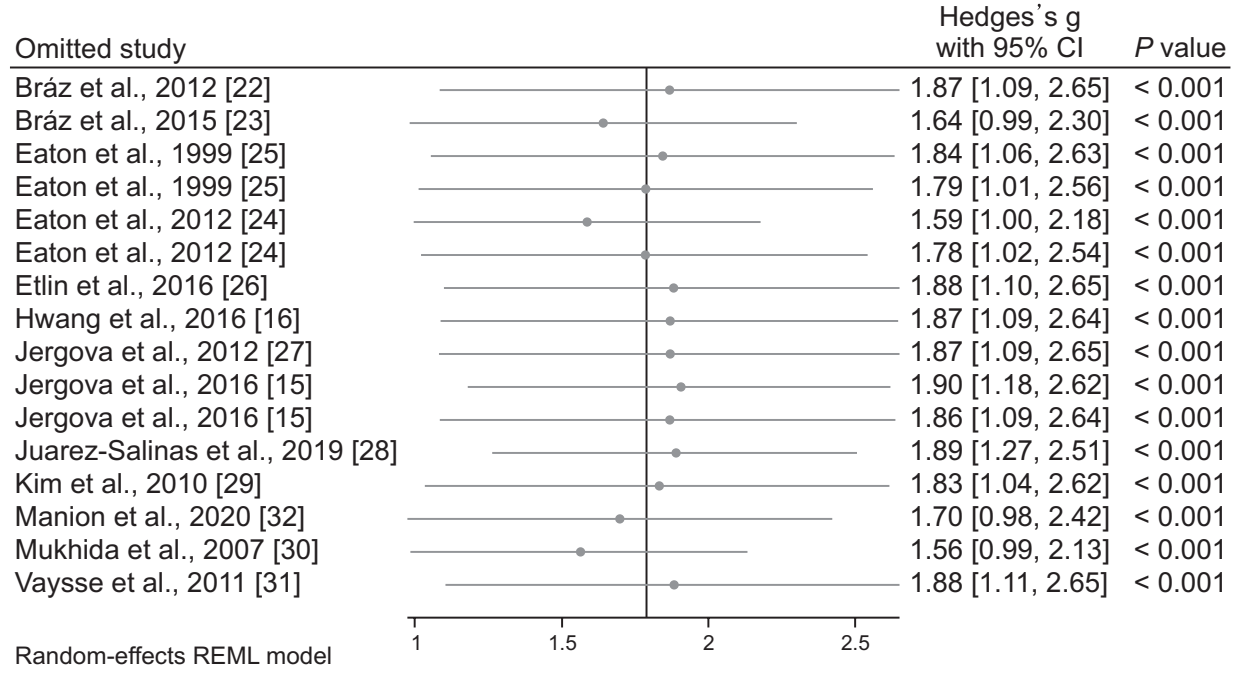

Fig. 5. Sensitivity analysis to assess individual studies' effect on efficacy of GABA cell transplantation on improvement of allodynia. Since, some included studies had more than one experiment, the number of experiments exceeded the number of studies. Cl: confidence interval.

\begin{tabular}{|c|c|c|c|}
\hline \multicolumn{2}{|l|}{ Omitted study } & $\begin{array}{l}\text { Hedges's g } \\
\text { with } 95 \% \mathrm{Cl}\end{array}$ & $P$ value \\
\hline Bráz et al., 2012 [22] & $\longrightarrow$ & $1.43[0.71,2.16]$ & $<0.001$ \\
\hline Bráz et al., 2015 [23] & $\rightarrow$ & $1.36[0.46,2.27]$ & 0.003 \\
\hline Eaton et al., 1999 [25] & $\rightarrow$ & $1.37[0.45,2.29]$ & 0.004 \\
\hline Eaton et al., 2012 [24] & & $1.19[0.39,1.99]$ & 0.004 \\
\hline Eaton et al., 2012 [24] & - & $0.97[0.40,1.54]$ & 0.001 \\
\hline Eaton et al., 2012 [24] & & $0.96[0.41,1.52]$ & 0.001 \\
\hline Jergova et al., 2012 [27] & - & $1.42[0.52,2.32]$ & 0.002 \\
\hline Jergova et al., 2012 [27] & - & $1.43[0.54,2.32]$ & 0.002 \\
\hline Jergova et al., 2016 [15] & - & $1.35[0.44,2.25]$ & 0.002 \\
\hline Jergova et al., 2016 [15] & - & $1.41[0.51,2.31]$ & 0.004 \\
\hline Vaysse et al., 2011 [31] & $\rightarrow$ & $1.40[0.49,2.31]$ & 0.002 \\
\hline Random-effects REML $n$ & 1.5 & & \\
\hline
\end{tabular}

Fig. 6. Sensitivity analysis to assess individual studies' effect on efficacy of GABA cell transplantation on improvement of hyperalgesia. Since, some included studies had more than one experiment, the number of experiments exceeded the number of studies. Cl: confidence interval. the mouse medial ganglionic eminence are not effective on the management of hyperalgesia. Consequently, it seems that the best sources of GABAergic cells in the management of neuropathic pain are genetically modified cells.

Nonetheless, concerns still exist regarding genetically modified cells. The possibility of genetic defects following genetic modification is still debated [33]. Adding a synthetic DNA sequence could cause dangerous mutations which are difficult to manage and may lead to serious consequences. Still, advances in tissue and gene engineering show promising results for adopting these techniques in the future.

This study has taken advantage of multiple subgroup analyses, performed to identify and possibly eliminate the significant difference in the articles, from a methodological point of view, to draw a conclusion with regards to these differences. The present study revealed that the efficacy of GABAergic cells in the management of hyperalgesia is only seen in rat subjects. This causes serious limitations to the generalization of the findings to other species. If such differences are observed between the two morphologically and genetically close species as rats and mice, then caution should be exercised in generalizing and translating these findings to future large animal studies or clinical trials.

The route of administration was also evaluated in in the present study. Overall, the method of injection was intraspinal in nine studies $[15,22-24,26,27,29,30,32]$ and intrathecal in three studies, while one study had transplanted the cells in the anterior cingulate cortex. Overall, the analyses revealed that the intraspinal administration method might be the desired route for the transplantation of GABAergic cells. However, the number of included studies administrating the cells intrathecally was low. Since intrathecal injection causes the least damage to the neural tissue, future studies may adopt this method and compare its efficacy with that of intraspinal or intracranial injection.

Various mechanisms are involved in the occurrence of neuropathic pain, the most important of which are neuropathy following SCI, diabetes, and chemotherapy [34,35]. Studies regarding all of these three mechanisms were included in the present study, and it was revealed that GABAergic cells improve the symptoms of neuropathic pain caused by all of the aforementioned mechanisms. 
In this setting, Eaton et al. [24] compared the effect of the transplantation of GABAergic cells in the following three neuropathic pain models in animals: streptozotocininduced neuropathic pain (diabetic induced neuropathic pain), CCI (peripheral neuropathic pain) and excitotoxic SCI (central neuropathic pain). The findings of this study showed that the administration of GABAergic cells alleviated neuropathic pain in all of the three models [24].

Regarding the effects of antibiotic and immunosuppressive administration on the efficacy of GABAergic precursor cells' transplantation, one could speculate that because of the possible beneficial effects of these two agents on alleviating the neuropathic pain, the difference of pain alleviation, in terms of allodynia and hyperalgesia, between the animals in the cell-treated group and the non-treated group was not significant. However, data regarding the matter is somewhat scarce, as few studies administered antibiotic and immunosuppressive treatments, which could be counted as a limitation of the present study. Hence, researchers are encouraged to gather more evidence about the effects of antibiotic and immunosuppressive administration on the efficacy of the GABAergic precursor cells' transplantation in the animal models.

As the paramount limitation of the present study, the number of studied animals, as well as the number of studies was significantly low, as only 317 animals were studied overall. Furthermore, much of the data was gathered from the same labs, which may affect the results regarding the efficacy of the GABAergic precursor cells' transplantation. As a result, to better reach a conclusion, a greater number of studies and experiments are needed.

Another limitation of the present systematic review was the low number of studies on the efficacy of GABAergic cells' transplantation in the management of central hyperalgesia and on the comparison of stem cell-derived GABAergic cells with other cell origins in analyses related to hyperalgesia. Hence, meta-analysis could not be performed in these two areas. Moreover, the quality assessment of the articles demonstrated that most of the included studies had high risk of bias in sequence generation, random housing, as well as caregiver and/or investigator blinding and random outcome assessment. However, these items are overlooked in most animal studies, and a review on all of these studies reveals that not reporting allocation concealment, random housing, caregivers and/ or investigators blinding and random outcome assessment is common. Thus, it is recommended that researchers be informed in this regard. Additionally, the risk of bias was unclear in selective outcome reporting in all the included studies. This could be attributable to the lack of an animal registry database. If such databases, similar to clinical trial registries, are created, selective outcome reporting 
could be largely monitored and reduced.

In conclusion, the present meta-analysis showed that administration of GABAergic cells alleviates allodynia and hyperalgesia in neuropathic pain models. However, it seems that the transplantation efficacy of these cells is only statistically significant in improving allodynia and hyperalgesia in rats, while such a positive effect was not observed in mouse studies. Therefore, caution should be exercised regarding the generalizability of findings from rat and mice studies to large animals and subsequent clinical trials. It was also concluded that genetically modified cells are the better source of GABAergic cells for management of neuropathic pain, compared to intrinsic GABAergic cells.

\section{CONFLICT OF INTEREST}

No potential conflict of interest relevant to this article was reported.

\section{FUNDING}

This research has been supported by Iran University of Medical Sciences.

\section{ORCID}

Shaghayegh Askarian-Amiri, https://orcid.org/0000-0001-8247-4485 Solmaz Nasseri Maleki, https://orcid.org/0000-0003-3290-4074 Seyedeh Niloufar Rafiei Alavi, https://orcid.org/0000-0001-5323-1708 Arian Madani Neishaboori, https://orcid.org/0000-0002-1920-9299 Amirmohammad Toloui, https://orcid.org/0000-0002-9809-0985

Mohammed I. M. Gubari, https://orcid.org/0000-0002-2873-3981

Arash Sarveazad, https://orcid.org/0000-0001-9273-1940

Mostafa Hosseini, https://orcid.org/0000-0002-1334-246X

Mahmoud Yousefifard, https://orcid.org/0000-0001-5181-4985

\section{REFERENCES}

1. Whalley K. Pain: transplanted precursors halt neuropathic pain. Nat Rev Neurosci 2012; 13: 447.

2. Tate DG, Forchheimer MB, Karana-Zebari D, Chiodo AE, Kendall Thomas JY. Depression and pain among inpatients with spinal cord injury and spinal cord disease: differences in symptoms and neurological function. Disabil Rehabil 2013; 35: 1204-12.

3. Kumru H, Soler D, Vidal J, Navarro X, Tormos JM, PascualLeone A, et al. The effects of transcranial direct current stimulation with visual illusion in neuropathic pain due to spinal cord injury: an evoked potentials and quantitative thermal testing study. Eur J Pain 2013; 17: 55-66.

4. Sharp K, Boroujerdi A, Steward O, Luo ZD. A rat chronic pain model of spinal cord contusion injury. Methods Mol Biol 2012; 851: 195-203.

5. Finnerup NB. Pain in patients with spinal cord injury. Pain 2013; 154 Suppl 1: S71-6.

6. Finnerup NB, Otto M, McQuay HJ, Jensen TS, Sindrup SH. Algorithm for neuropathic pain treatment: an evidence based proposal. Pain 2005; 118: 289-305.

7. Backonja MM, Irving G, Argoff C. Rational multidrug therapy in the treatment of neuropathic pain. Curr Pain Headache Rep 2006; 10: 34-8.

8. Marineo G, Iorno V, Gandini C, Moschini V, Smith TJ. Scrambler therapy may relieve chronic neuropathic pain more effectively than guideline-based drug management: results of a pilot, randomized, controlled trial. J Pain Symptom Manage 2012; 43: 87-95.

9. Wolfe D, Mata M, Fink DJ. Targeted drug delivery to the peripheral nervous system using gene therapy. Neurosci Lett 2012; 527: 85-9.

10. Eaton MJ, Martinez MA, Karmally S. A single intrathecal injection of GABA permanently reverses neuropathic pain after nerve injury. Brain Res 1999; 835: 334-9.

11. Polgár E, Todd AJ. Tactile allodynia can occur in the spared nerve injury model in the rat without selective loss of GABA or GABA(A) receptors from synapses in laminae I-II of the ipsilateral spinal dorsal horn. Neuroscience 2008; 156: 193-202.

12. McLeod MC, Kobayashi NR, Sen A, Baghbaderani BA, Sadi D, Ulalia R, et al. Transplantation of GABAergic cells derived from bioreactor-expanded human neural precursor cells restores motor and cognitive behavioral deficits in a rodent model of Huntington's disease. Cell Transplant 2013; 22: 2237-56.

13. Shetty AK, Bates A. Potential of GABA-ergic cell therapy for schizophrenia, neuropathic pain, and Alzheimer's and Parkinson's diseases. Brain Res 2016; 1638(Pt A): 74-87.

14. Jergova S, Gajavelli S, Pathak N, Sagen J. Recombinant neural progenitor transplants in the spinal dorsal horn alleviate chronic central neuropathic pain. Pain 2016; 157: 977-89.

15. Jergova S, Gajavelli S, Varghese MS, Shekane P, Sagen J. Analgesic effect of recombinant GABAergic cells in a model of peripheral neuropathic pain. Cell Transplant 2016; 25: 62943.

16. Hwang I, Hahm SC, Choi KA, Park SH, Jeong H, Yea JH, et al. Intrathecal transplantation of embryonic stem cell-derived spinal GABAergic neural precursor cells attenuates neuropathic pain in a spinal cord injury rat model. Cell Transplant 2016; 25: 593-607.

17. Sistrom CL, Mergo PJ. A simple method for obtaining original data from published graphs and plots. AJR Am J Roent- 
genol 2000; 174: 1241-4.

18. Hooijmans CR, Rovers MM, de Vries RB, Leenaars M, Ritskes-Hoitinga M, Langendam MW. SYRCLE's risk of bias tool for animal studies. BMC Med Res Methodol 2014; 14: 43.

19. Wei D, Tang K, Wang Q, Estill J, Yao L, Wang X, et al. The use of GRADE approach in systematic reviews of animal studies. J Evid Based Med 2016; 9: 98-104.

20. IntHout J, Ioannidis JP, Borm GF. The Hartung-KnappSidik-Jonkman method for random effects meta-analysis is straightforward and considerably outperforms the standard DerSimonian-Laird method. BMC Med Res Methodol 2014; 14: 25 .

21. Wang D, Mou ZY, Zhai JX, Zong HX, Zhao XD. [Application of Stata software to test heterogeneity in meta-analysis method]. Zhonghua Liu Xing Bing Xue Za Zhi 2008; 29: 7269. Chinese.

22. Bráz JM, Sharif-Naeini R, Vogt D, Kriegstein A, Alvarez-Buylla A, Rubenstein JL, et al. Forebrain GABAergic neuron precursors integrate into adult spinal cord and reduce injuryinduced neuropathic pain. Neuron 2012; 74: 663-75.

23. Bráz JM, Wang X, Guan Z, Rubenstein JL, Basbaum AI. Transplant-mediated enhancement of spinal cord GABAergic inhibition reverses paclitaxel-induced mechanical and heat hypersensitivity. Pain 2015; 156: 1084-91.

24. Eaton MJ, Berrocal Y, Wolfe SQ. Potential for cell-transplant therapy with human neuronal precursors to treat neuropathic pain in models of PNS and CNS injury: comparison of hNT2.17 and hNT2.19 cell lines. Pain Res Treat 2012; 2012: 356412.

25. Eaton MJ, Plunkett JA, Martinez MA, Lopez T, Karmally S, Cejas $\mathrm{P}$, et al. Transplants of neuronal cells bioengineered to synthesize GABA alleviate chronic neuropathic pain. Cell Transplant 1999; 8: 87-101.

26. Etlin A, Bráz JM, Kuhn JA, Wang X, Hamel KA, LlewellynSmith IJ, et al. Functional synaptic integration of forebrain
GABAergic precursors into the adult spinal cord. J Neurosci 2016; 36: 11634-45.

27. Jergova S, Hentall ID, Gajavelli S, Varghese MS, Sagen J. Intraspinal transplantation of GABAergic neural progenitors attenuates neuropathic pain in rats: a pharmacologic and neurophysiological evaluation. Exp Neurol 2012; 234: 39-49.

28. Juarez-Salinas DL, Braz JM, Etlin A, Gee S, Sohal V, Basbaum AI. GABAergic cell transplants in the anterior cingulate cortex reduce neuropathic pain aversiveness. Brain 2019; 142: 2655-69.

29. Kim DS, Jung SJ, Nam TS, Jeon YH, Lee DR, Lee JS, et al. Transplantation of GABAergic neurons from ESCs attenuates tactile hypersensitivity following spinal cord injury. Stem Cells 2010; 28: 2099-108.

30. Mukhida K, Mendez I, McLeod M, Kobayashi N, Haughn C, Milne B, et al. Spinal GABAergic transplants attenuate mechanical allodynia in a rat model of neuropathic pain. Stem Cells 2007; 25: 2874-85.

31. Vaysse L, Sol JC, Lazorthes Y, Courtade-Saidi M, Eaton MJ, Jozan S. GABAergic pathway in a rat model of chronic neuropathic pain: modulation after intrathecal transplantation of a human neuronal cell line. Neurosci Res 2011; 69: 111-20.

32. Manion J, Khuong T, Harney D, Littleboy JB, Ruan T, Loo L, et al. Human induced pluripotent stem cell-derived GABAergic interneuron transplants attenuate neuropathic pain. Pain 2020; 161: 379-87.

33. Bao S, Lv Z, Li Y, Ma J, Zhang Y, Li S, et al. Genetic engineering: pros versus cons in deciphering disease mechanism. Sci Insights 2016; 2016: e00258.

34. Colloca L, Ludman T, Bouhassira D, Baron R, Dickenson AH, Yarnitsky D, et al. Neuropathic pain. Nat Rev Dis Primers 2017; 3: 17002.

35. Meacham K, Shepherd A, Mohapatra DP, Haroutounian S. Neuropathic pain: central vs. peripheral mechanisms. Curr Pain Headache Rep 2017; 21: 28. 


\section{Appendices}

Appendix 1. Search strategy in present study

Database

MEDLINE (PubMed) (("GABAergic Neurons"[Mesh] OR GABAergic Neurons[tiab] OR GABAergic Neuron[tiab] OR Neuron, GABAergic[tiab] OR Neurons, GABAergic[tiab] OR GABAergic neuron precursors[tiab] OR GABA Cells[tiab] OR Cell, GABA[tiab] OR Cells, GABA[tiab] OR GABA Cell[tiab] OR GABA Neurons[tiab] OR GABA Neuron[tiab] OR Neuron, GABA[tiab] OR Neurons, GABA[tiab] OR GABAergic Precursors[tiab] OR Predifferentiated GABAergic[tiab] OR GABAergic Cells[tiab] OR GABAergic inhibition [tiab] OR GABAergic Transplants[tiab] OR neural precursor cells[tiab] OR GABAergic neuron precursors [tiab] OR 4 aminobutyrate receptor[tiab] OR 4 aminobutyric acid nerve cell[tiab] OR gaba nerve cell[tiab] OR GABA receptor[tiab] OR gabaergic nerve cell[tiab] OR GABAergic neuron[tiab] OR GABAergic neurons[tiab] OR gamma aminobutyrate receptor[tiab] OR gamma aminobutyric acid receptor[tiab] OR nerve cell, gaba[tiab] OR receptors, gaba[tiab] OR GABAergic neurons[tiab] OR GABAergic inhibitory neuron precursors[tiab] OR GABAergic Interneurons[tiab] OR interneuron precursors[tiab])) AND ("spinal cord injury"[MeSH] OR "spinal cord contusion"[MeSH] OR "spinal cord hemisection"[MeSH] OR "spinal cord transection"[MeSH] OR "cervical spine injury"[MeSH] OR spinal cord injury[tiab] OR spinal cord contusion[tiab] OR spinal cord hemisection[tiab] OR spinal cord transaction[tiab] OR cervical spine injury[tiab] OR Spinal compression[tiab] OR spinal cord trauma[tiab] OR trauma, spinal cord[tiab] OR injured spinal cord[tiab] OR spinal cord injured[tiab] OR spinal cord injuries[tiab] OR nerve transection[tiab] OR pain"[Mesh] OR "pain[tiab] OR neuropathic pain"[Mesh] OR "neuropathic pain[tiab] OR allodynia[tiab] OR hyperalgesia[tiab] OR hypersensitivity[tiab] OR nociception[tiab])

EMBASE 1. 'GABAergic Neurons':ab,ti OR 'GABAergic Neuron':ab,ti OR 'Neuron, GABAergic':ab,ti OR 'Neurons, GABAergic':ab,ti OR 'GABAergic neuron precursors':ab,ti OR 'GABA Cells':ab,ti OR 'Cell, GABA':ab,ti OR 'Cells, GABA':ab,ti OR 'GABA Cell':ab,ti OR 'GABA Neurons':ab,ti OR 'GABA Neuron':ab,ti OR 'Neuron, GABA':ab,ti OR 'Neurons, GABA':ab,ti OR 'GABAergic Precursors':ab,ti OR 'Predifferentiated GABAergic':ab,ti OR 'GABAergic Cells':ab,ti OR 'GABAergic inhibition ':ab,ti OR 'GABAergic Transplants':ab,ti OR 'neural precursor cells':ab,ti OR 'GABAergic neuron precursors ':ab,ti OR '4 aminobutyrate receptor':ab,ti OR '4 aminobutyric acid nerve cell':ab,ti OR ' gaba nerve cell':ab,ti OR ' GABA receptor':ab,ti OR ' gabaergic nerve cell':ab,ti OR ' GABAergic neuron':ab,ti OR ' GABAergic neurons':ab,ti OR ' gamma aminobutyrate receptor':ab,ti OR ' gamma aminobutyric acid receptor':ab,ti OR ' nerve cell, gaba':ab,ti OR ' receptors, gaba':ab,ti OR 'GABAergic neurons':ab,ti OR 'GABAergic inhibitory neuron precursors':ab,ti OR 'GABAergic Interneurons':ab,ti OR 'interneuron precursors':ab,ti

2. 'spinal cord injury'/exp OR 'spinal cord contusion'/exp OR 'spinal cord hemisection'/exp OR 'spinal cord transaction'/exp OR 'cervical spine injury'/exp OR 'pain'/exp OR ' neuropathic pain'/exp OR 'Spinal compression':ab,ti OR 'spinal cord trauma':ab,ti OR 'trauma, spinal cord':ab,ti OR 'injured spinal cord':ab,ti OR 'spinal cord injured':ab,ti OR 'spinal cord injuries':ab,ti OR 'nerve transection':ab,ti OR 'allodynia':ab,ti OR 'hyperalgesia':ab,ti OR 'hypersensitivity':ab,ti OR 'nociception':ab,ti

3. \#1 AND \#2

Scopus ( ( ( TITLE-ABS-KEY ( "GABAergic Neurons" ) OR TITLE-ABS-KEY ( "GABAergic Neuron" ) OR TITLE-ABS-KEY ( "Neuron, GABAergic" ) OR TITLE-ABS-KEY ( "Neurons, GABAergic" ) OR TITLE-ABS-KEY ( "GABAergic neuron precursors" ) OR TITLE-ABS-KEY ( "GABA Neurons" ) OR TITLE-ABS-KEY ( "GABA Neuron" ) OR TITLE-ABS-KEY ( "Neuron, GABA" ) OR TITLE-ABS-KEY ( "Neurons, GABA" ) OR TITLE-ABS-KEY ( "GABAergic Precursors" ) OR TITLE-ABS-KEY ( "Predifferentiated GABAergic") OR TITLE-ABS-KEY ( "GABAergic Cells" ) OR TITLE-ABS-KEY ( "GABAergic inhibition ") OR TITLE-ABS-KEY ( "GABAergic Transplants" ) OR TITLE-ABSKEY ( "neural precursor cells" ) OR TITLE-ABS-KEY ( "GABAergic neuron precursors ") OR TITLE-ABS-KEY ( "4 aminobutyrate receptor" ) OR TITLE-ABS-KEY ( "4 aminobutyric acid nerve cell" ) OR TITLE-ABS-KEY ( "gaba nerve cell" ) OR TITLE-ABS-KEY ( " GABA receptor" ) OR TITLE-ABS-KEY ( "gabaergic nerve cell" ) OR TITLE-ABS-KEY ( "GABAergic neuron" ) OR TITLE-ABS-KEY ( "GABAergic neurons" ) OR TITLE-ABS-KEY ( "gamma aminobutyrate receptor" ) OR TITLE-ABS-KEY ( " gamma aminobutyric acid receptor" ) OR TITLE-ABS-KEY ( " nerve cell, gaba" ) OR TITLE-ABS-KEY ( "receptors, gaba" ) OR TITLE-ABS-KEY ( "GABAergic neurons" ) OR TITLE-ABS-KEY ( "GABAergic inhibitory neuron precursors" ) ) ) AND ( ( TITLE-ABS-KEY ( "spinal cord injury" ) OR TITLE-ABS-KEY ( "Spinal cord injuries" ) OR TITLE-ABS-KEY ( "spinal cord contusion" ) OR TITLE-ABS-KEY ( "spinal cord hemisection" ) OR TITLE-ABS-KEY ( "spinal cord transaction" ) OR TITLE-ABS-KEY ( "cervical spine injury" ) OR TITLE-ABS-KEY ( "Spinal compression" ) OR TITLE-ABS-KEY ( "spinal cord trauma" ) OR TITLE-ABS-KEY ( "injured spinal cord" ) OR TITLE-ABSKEY ( "spinal cord injured" ) OR TITLE-ABS-KEY ( "nerve transection" ) OR TITLE-ABS-KEY ( "neuropathic pain" ) OR TITLE-ABSKEY ( "allodynia" ) OR TITLE-ABS-KEY ( "hyperalgesia" )) ))

Web of Science $\quad$ 1. TS=( "GABAergic Neurons" OR "GABAergic Neuron" OR "Neuron, GABAergic" OR "Neurons, GABAergic" OR "GABAergic neuron precursors" OR "GABA Cells" OR "Cell, GABA" OR "Cells, GABA" OR "GABA Cell" OR "GABA Neurons" OR "GABA Neuron" OR "Neuron, GABA" OR "Neurons, GABA" OR "GABAergic Precursors" OR "Predifferentiated GABAergic" OR "GABAergic Cells" OR "GABAergic inhibition " OR "GABAergic Transplants" OR "neural precursor cells" OR "GABAergic neuron precursors " OR "4 aminobutyrate receptor" OR "4 aminobutyric acid nerve cell" OR " gaba nerve cell" OR " GABA receptor" OR " gabaergic nerve cell" OR " GABAergic neuron" OR " GABAergic neurons" OR " gamma aminobutyrate receptor" OR " gamma aminobutyric acid receptor" OR " nerve cell, gaba" OR " receptors, gaba" OR "GABAergic neurons" OR "GABAergic inhibitory neuron precursors" )

2. TS=( "spinal cord injury" OR "Spinal cord injuries" OR "spinal cord contusion" OR "spinal cord hemisection" OR "spinal cord transsection" OR "cervical spine injury" OR "Spinal compression" OR "spinal cord trauma" OR "injured spinal cord" OR "spinal cord injured" OR "nerve transection" OR "neuropathic pain" OR "allodynia" OR "hyperalgesia" OR "nociception" )

3. \#1 AND \#2 
Appendix 2. The list of excluded studies

\section{No cell therapies}

1. Ang ST, Lee AT, Foo FC, Ng L, Low CM, Khanna S. GABAergic neurons of the medial septum play a nodal role in facilitation of nociception-induced affect. Sci Rep 2015; 5: 15419.

2. Cao J, Yang X, Liu YN, Suo ZW, Shi L, Zheng CR, et al. GABAergic disinhibition induced pain hypersensitivity by upregulating NMDA receptor functions in spinal dorsal horn. Neuropharmacology 2011; 60: 921-9.

3. Chattopadhyay M, Mata M, Fink DJ. Vector-mediated release of GABA attenuates pain-related behaviors and reduces Na(V)1.7 in DRG neurons. Eur J Pain 2011; 15: 913-20.

4. Kanao M, Kanda H, Huang W, Liu S, Yi H, Candiotti KA, et al. Gene transfer of glutamic acid decarboxylase 67 by herpes simplex virus vectors suppresses neuropathic pain induced by human immunodeficiency virus gp120 combined with ddC in rats. Anesth Analg 2015; 120: 1394-404.

5. Kanda H, Kanao M, Liu S, Yi H, Iida T, Levitt RC, et al. HSV vector-mediated GAD67 suppresses neuropathic pain induced by perineural HIV gp120 in rats through inhibition of ROS and Wnt5a. Gene Ther 2016; 23: 340-8.

6. Liu W, Liu Z, Liu L, Xiao Z, Cao X, Cao Z, et al. A novel human foamy virus mediated gene transfer of GAD67 reduces neuropathic pain following spinal cord injury. Neurosci Lett 2008; 432: 13-8.

7. Wang YY, Wei YY, Huang J, Wang W, Tamamaki N, Li YQ, et al. Expression patterns of 5-HT receptor subtypes 1A and $2 A$ on GABAergic neurons within the spinal dorsal horn of GAD67-GFP knock-in mice. J Chem Neuroanat 2009; 38: 75-81.

\section{No GABA}

8. Batista CM, Mariano ED, Dale CS, Cristante AF, Britto LR, Otoch JP, et al. Pain inhibition through transplantation of fetal neuronal progenitors into the injured spinal cord in rats. Neural Regen Res 2019; 14: 2011-9.

\section{No pain assessment}

9. Lee JW, Jergova S, Furmanski O, Gajavelli S, Sagen J. Predifferentiated GABAergic neural precursor transplants for alleviation of dysesthetic central pain following excitotoxic spinal cord injury. Front Physiol 2012; 3: 167.

10. Llewellyn-Smith IJ, Basbaum AI, Bráz JM. Long-term, dynamic synaptic reorganization after GABAergic precursor cell transplantation into adult mouse spinal cord. J Comp Neurol 2018; 526: 480-95.

11. Braz JM, Juarez-Salinas D, Ross SE, Basbaum AI. Transplant restoration of spinal cord inhibitory controls ameliorates neuropathic itch. J Clin Invest 2014; 124: 3612-6.

12. Cao QL, Howard RM, Dennison JB, Whittemore SR. Differentiation of engrafted neuronal-restricted precursor cells is inhibited in the traumatically injured spinal cord. Exp Neurol 2002; 177: 349-59.

\section{Review articles}

13. Basbaum AI, Bráz JM. Cell transplants to treat the "disease" of neuropathic pain and itch. Pain 2016; 157(Suppl 1): S42-7.

14. Shetty AK, Bates A. Potential of GABA-ergic cell therapy for schizophrenia, neuropathic pain, and Alzheimer's and Parkinson's diseases. Brain Res 2016; 1638(Pt A): 74-87.

\section{Not related}

15. Ducray AD, Schläppi JA, Qualls R, Andres RH, Seiler RW, Schlattner U, et al. Creatine treatment promotes differentiation of GABA-ergic neuronal precursors in cultured fetal rat spinal cord. J Neurosci Res 2007; 85: 1863-75.

16. Viggiano A, Monda M, Viggiano A, Chiefari M, Aurilio C, De Luca B. Evidence that GABAergic neurons in the spinal trigeminal nucleus are involved in the transmission of inflammatory pain in the rat: a microdialysis and pharmacological study. Eur J Pharmacol 2004; 496: 87-92.

17. Vergnano AM, Schlichter R, Poisbeau P. PKC activation sets an upper limit to the functional plasticity of GABAer- 
gic transmission induced by endogenous neurosteroids. Eur J Neurosci 2007; 26: 1173-82.

18. Ultenius C, Song Z, Lin P, Meyerson BA, Linderoth B. Spinal GABAergic mechanisms in the effects of spinal cord stimulation in a rodent model of neuropathic pain: is GABA synthesis involved? Neuromodulation 2013; 16: 11420.

19. Huang J, Wang YY, Wang W, Li YQ, Tamamaki N, Wu SX. 5-HT(3A) receptor subunit is expressed in a subpopulation of GABAergic and enkephalinergic neurons in the mouse dorsal spinal cord. Neurosci Lett 2008; 441: 1-6.

20. Dromard C, Guillon H, Rigau V, Ripoll C, Sabourin JC, Perrin FE, et al. Adult human spinal cord harbors neural precursor cells that generate neurons and glial cells in vitro. J Neurosci Res 2008; 86: 1916-26.

21. Meisner JG, Marsh AD, Marsh DR. Loss of GABAergic interneurons in laminae I-III of the spinal cord dorsal horn contributes to reduced GABAergic tone and neuropathic pain after spinal cord injury. J Neurotrauma 2010; 27: 729-37.

22. Shechter R, Ziv Y, Schwartz M. New GABAergic interneurons supported by myelin-specific T cells are formed in intact adult spinal cord. Stem Cells 2007; 25: 2277-82.

23. Hains BC, Johnson KM, Eaton MJ, Willis WD, Hulsebosch CE. Serotonergic neural precursor cell grafts attenuate bilateral hyperexcitability of dorsal horn neurons after spinal hemisection in rat. Neuroscience 2003; 116: 1097110.

24. Fandel TM, Trivedi A, Nicholas CR, Zhang H, Chen J, Martinez AF, et al. Transplanted human stem cell-derived interneuron precursors mitigate mouse bladder dysfunction and central neuropathic pain after spinal cord injury. Cell Stem Cell 2016; 19: 544-57.

25. Carelli S, Giallongo T, Marfia G, Merli D, Ottobrini L, Degrassi A, et al. Exogenous adult postmortem neural precursors attenuate secondary degeneration and promote myelin sparing and functional recovery following experimental spinal cord injury. Cell Transplant 2015; 24: 703-19.

26. Baba H, Ji RR, Kohno T, Moore KA, Ataka T, Wakai A, et al. Removal of GABAergic inhibition facilitates polysynaptic A fiber-mediated excitatory transmission to the superficial spinal dorsal horn. Mol Cell Neurosci 2003; 24: 81830 . 